\title{
Coleções, silêncios, higienização e hegemonia de classes - uma análise sobre os casos de Inhotim (Brasil) e Saint Louis Art Museum (EUA)
}

\author{
Marina Roriz Rizzo Lousa da Cunha \\ Professora Doutora da Universidade Federal de Goiás, Goiânia, Brasil \\ roriz.marina@gmail.com
}

Resumo Nocontexto contemporâneo, muitos museus de arte caminham para se estruturarem com foco na lógica de mercado e nas demandas de uma economia globalizada, ocasionando práticas mais inclusivas, dialógicas, tecnológicas, concentradas em volumes de audiência. No entanto, ao olhar para as coleções expostas nestas instituições, é possível observar que, apesar de uma suposta abertura democrática, estes objetos tendem a ser indexados em referentes específicos, e em muitos casos, sofrerem processos de higienização e silenciamento, reforçando a relação desigual entre quem mostra e quem é mostrado. Para entender melhor esta situação, este artigo concentrase na análise de dois casos, o Instituto Inhotim (Brasil) e o Saint Louis Art Museum (EUA). Procura entender o papel das coleções ali presentes a fim de evidenciar, a partir da relação entre investigadores e interlocutores, as redes e posições que se constituem. Esta pesquisa contou com financiamento da Capes - Processo n BEX 8876/14-2.

Palavras-chave: Abertura democrática, coleções, higienização, silêncios, hegemonia de classes.

As transformações econômicas, sociais, culturais e políticas advindas com a contemporaneidade alteraram em muitos aspectos o modo como os museus de arte são concebidos na atualidade. Eles parecem se revestir de uma nova roupagem, que os adapta a ótica de mercado, os tornando muito próximos dos meios de comunicação de massa, local onde, aparentemente, novas vozes emergem 
com poder de autoridade. ${ }^{1}$ Esta nova roupagem está sujeita a uma dinâmica capitalista, que exige o entendimento e o direcionamento das instituições para o foco na audiência. Apesar dessa nova formatação, supõe-se que atuam pela mesma finalidade desde que foram instituídos: são instrumentos de consagração da ordem social, visando a construção e a manutenção da hegemonia de uma classe sobre as demais.

Analisando os casos propostos (Inhotim² e Saint Louis Art Museum³ ${ }^{3}$ foi possível perceber que os museus de arte estudados estão sujeitos a processos de hibridação ${ }^{4}$ e vêm, cotidianamente, se adequando a ótica mercadológica trazida pela contemporaneidade. Neste sentido, se revestem, cada vez mais, com características de indústria. Sua principal alteração se dá a partir do atendimento prioritário das demandas do mercado, se destacando a formação de audiências.

Nesta direção, aspectos como a busca por contextos globais, novas fontes de financiamento, gestão de estratégias de viabilidade financeira, maior exigência de qualificação de seu quadro de trabalhadores, desenvolvimento de instrumentos que favoreçam a captação de grandes audiências, estruturação de produtos culturais sujeitos a um ciclo de renovação constante e as demandas por experiências exclusivas, personalizadas e multissensoriais, são características presentes, tornando as instituições analisadas cada vez mais próximas de meios de comunicação de massa. A atividade cultural, nestes locais, submete-se aos padrões e critérios do mundo do consumo. Aceita as condições impostas. Justifica-se em termos de seu valor. $O$ foco passa a se estabelecer a partir das experiências empáticas e não mais do conhecimento cultural. O sucesso se estabelece pelo volume de audiência e pelo peso das marcas patrocinadoras que se consegue atrair.

Colaboram com esse fato a reconfiguração das instituições culturais, a partir de uma aparente democratização do acesso e das vozes de autoridade, passando a impressão de se estar havendo a redução de barreiras exclusivistas e aristocratas. Para Marcuse (1997), no entanto, trata-se da cultura, afirmando e ocultando as novas condições sociais da vida, do deslocamento da fruição artística de suas funções rituais para um conjunto de finalidades políticas.

1 Para compreender melhor esta análise, checar: CUNHA, Marina. Quando o mercado invade o museu. A dinâmica das instituições culturais da pós-modernidade: os casos de Inhotim (Brasil) e Saint Louis Art Museum (EUA). 2017. 650 f. Tese (Doutorado em Sociologia) - Faculdade de Ciências Sociais, Universidade Federal de Goiás, Goiânia, 2017.

2 Inhotim é considerado um instituto que mescla arte, botânica e cultura, sendo sede de um dos mais importantes acervos de arte contemporânea do Brasil e o maior centro de arte ao livre da América Latina. Está localizado em Brumadinho, Minas Gerais, a apenas $60 \mathrm{~km}$ de Belo Horizonte.

3 O Saint Louis Art Museum é um dos principais museus de arte americano, contando com um acervo repleto de pinturas, esculturas, objetos culturais e antiguidades de todas as partes do mundo. Está localizado em Saint Louis, Missouri, e é visitado por mais de meio milhão de pessoas por ano.

4 Canclini denomina de hibridação os "processos socioculturais nas quais estruturas ou práticas discretas, que existiam de forma separada, se combinam para gerar novas estruturas, objetos e práticas" (Canclini, 2008, p. XIX). 
No contexto de hiper-mercantilização presente na contemporaneidade, o museu de arte vem deixando de ser um espaço comandado pelas mãos do Estado para fluir, cada vez mais, para as mãos da sociedade civil. Um agente que aos poucos se estabelece como um dos novos mecanismos de participação econômica, social e política, atendendo as condições de um novo contexto histórico. Neste âmbito, a sociedade civil atua visando reconciliar os interesses privados com um bem comum. Faz isso, no entanto, a partir da lógica de mercado. Uma democratização mercantil, em que a participação é medida pelo poder aquisitivo, e porque não, pelo papel alcançado pelo dinheiro como mediador principal das relações psicossociais (Benbenaste, 2006).

Uma democratização, portanto, limitada. Seus limites são impostos tanto pelo enfraquecimento do financiamento pelo Estado e pela elite quanto pelo fato destas instituições geralmente serem administradas pela classe privilegiada. No primeiro limitador, o Estado e a elite não mais conseguem financiar sozinhos a maior parte das instituições culturais. O mercado é chamado a intervir. No segundo, a classe privilegiada nem sempre é portadora de interesses e valores que estão ligados a emancipação humana e a construção de mecanismos de fortalecimento da cidadania e da democracia.

Para além de se revestirem de uma nova roupagem, as instituições culturais contemporâneas estudadas parecem precisar adequar seus discursos e práticas, a fim de criarem rótulos reconhecíveis. Estes rótulos atuam classificando e ordenando, de forma natural e naturalizante os valores e crenças aos quais se procura legitimar. Discurso e prática ajudam a reforçar um modo de ação sobre o mundo e sobre os indivíduos, construindo significados e uma forma de pensar e de tomar decisões. De maneira invisível, as instituições conferem uniformidade, sobrecarregam um conteúdo moral e político capaz de criar realidades e estabilizar o fluxo da vida social.

Os discursos e as práticas atuam no processo de construção e representação do mundo, "produzindo uma rede de significados e sentidos" (Marchiori, 2009, p. 10). São modos de ação, nos diz Fairclough (2001), maneiras pelas quais se permite agir sobre o mundo e sobre os outros indivíduos construindo significados. Ferramentas através das quais as pessoas agem sobre as outras. Instrumentos capazes de permitir que os indivíduos sejam moldados pelas práticas discursivas existentes nas organizações. Estes elementos não são simplesmente as lutas ou sistemas de dominação, mas sim, "aquilo pelo que se luta, o poder do qual nós queremos apoderar" (Foucalt, 1999, p. 10). Sua produção é controlada, selecionada, organizada e redistribuída. Possui ligação direta com o desejo, com o poder, com a profetização do futuro, contribuindo para a adesão dos homens. São uma espécie de pressão e de instrumentos de coerção.

Sendo assim, práticas e discursos institucionais naturalizam as classificações sociais, tornam as estruturas formais recorrentes, facilmente reconhecidas e revestidas de uma verdade que se autolegitima. Ao mesmo tempo, estimulam os indivíduos a procurarem e selecionarem entre as analogias existentes, aquelas a que darão crédito, em vista de definirem seus aliados e adversários, bem como o padrão de suas futuras relações. As 
instituições, assim, controlam a constituição de sua sociedade, construindo uma máquina de pensar e de tomar decisões (Douglas, 1998).

Desta forma, os valores institucionais são apresentados, cotidianamente, de diferentes maneiras. Nas práticas diárias, nos materiais de divulgação e também a partir das coleções. Neste aspecto, as coleções são trabalhadas de forma a revelarem representações específicas, muitas vezes recontextualizadas, ressignificadas. Objetos são deslocados de seus sentidos originais, ganham novas acepções, dependendo da ocasião e dos interesses. E qual a finalidade da ressignificação de objetos? O ressignificar permite que os sujeitos se percebam e experimentem subjetivamente suas posições e identidades como elementos reais e concretos, assim como os objetos que os simbolizam. O passado é recuperado e recontado a partir de um olhar específico. Silêncios são instituídos e, nesta direção, eventos e fatos são recuperados, sujeitos a evidenciações e interpretações de forma a assumirem uma certa maneira de ler a história e produzir um tipo de conhecimento. Na opinião de Carvalho (2004), ao atuarem assim, as instituições exercem uma atitude de impunidade estética, isto é, se apropriam de elementos nativos, invadindo seu espaço, em uma tentativa de performar para si mesmas, reforçando a impressão de que aquela cultura lhe pertence. Trata-se de um movimento de apropriação completa de uma arte cultivada por outro estrato social e racial, em que um filtro social e político da experiência estético-simbólica de uma comunidade ou etnia, de outra classe ou de outro grupo racial, é capturado e anexado ao patrimônio cultural de um grupo social específico. Mais do que uma questão de ressignificação de símbolos tradicionais, refere-se a um modo de expropriação de tradições.

Constrói-se assim um novo consenso, a partir do qual as instituições elaboram e difundem suas ideologias, definindo os parâmetros pelos quais os homens concebem o universo em que vivem, a forma como enxergam situações e impondo uma visão de mundo estratégica. Serão responsáveis por gerar um sistema de significados e valores, experimentados na prática cotidiana, que contribuirão para as expectativas sobre a totalidade da vida.

Se de um lado, discursos e práticas atuam para conferir rótulos e reforçar identidades, os silêncios também podem atuar nesta mesma direção. As histórias são produzidas em um contexto histórico específico, e os seres humanos delas participam como atores e narradores. Ao participar destes processos, os homens destacam ou omitem fatos e objetos que afetam diretamente a percepção sobre essas histórias. Nesta direção, Trouillot (2015) defende que os sentidos, a interpretação que se tem sobre determinada história é gerada a partir de três perspectivas. A primeira é dada pela ênfase sócio-histórica do processo. A segunda, ao conhecimento que se tem sobre esse processo, isto é, a estória que se conhece sobre ele. Já a terceira, "[...] é possível apenas porque reconhecemos implicitamente uma sobreposição entre o processo sócio-histórico e nosso conhecimento"5 (Trouillot, 2015,p. the sociohistorical process and our knowledge of it." (Tradução do autor). 
3). Entre a história e o conhecimento, no entanto, existem camadas de teorias acumuladas ao longo das décadas, dos séculos. Teorias construídas a partir de palavras.

Palavras estas geralmente atribuídas por quem detém o poder."Na melhor das hipóteses, a história é uma história sobre o poder, uma história sobre quem ganhou"6 (Trouillot,2015,p. 5). E como tal, em sua versão dominante, "sustenta que a narrativa histórica ignora a questão da verdade em virtude da sua forma. As narrativas são necessariamente desempenhadas de uma maneira que a vida não é"7 (Trouillot, 2015, p. 6).

Histórias narradas necessitam, portanto, ganhar força de verdade. É imprescindível estabelecer uma autoridade moral. Precisam de algum tipo de credibilidade para poder passar de ficção a fato real. E neste movimento,

Grupos historicamente específicos de seres humanos devem decidir se uma narrativa específica pertence à história ou à ficção. Em outras palavras, a ruptura epistemológica entre história e ficção sempre é expressa concretamente através da avaliação historicamente situada de narrativas específicas ${ }^{8}$ (Trouillot, 2015, p. 8).

Neste sentido, para cada classe, têm-se determinadas regras vigentes. Serão estas regras que estabelecerão os parâmetros pelos quais as situações serão descritas. Neste movimento de construção de histórias, fatos e personagens são destacados e outros silenciados. Price (2016) concorda, para ela, qualquer narrativa histórica é sempre um conjunto particular de silêncios.

Os silêncios, diz Trouillot (2015), podem adentrar no processo de produção histórica em quatro momentos cruciais: na criação dos fatos (the making of sources); na montagem do fato, isto é, em sua organização institucionalizada e elaboração da possibilidade de existência como declaração histórica (the making of archives); na recuperação dos fatos (the making of narratives), uma vez que pesos, riqueza de detalhes e frequências diferentes podem ser utilizados para cada fato em especial; e no momento da retrospectiva do significado (the making of history in the final instance). Desta forma, defende que é possível perceber que os silêncios não são todos iguais e não são constituídos da mesma forma. "Qualquer narrativa histórica é um feixe particular de silêncios, resultado de processos únicos. As operações necessárias para desconstruir esses silêncios serão variadas"9 (Trouillot, 2015, p. 27). Para cada caso, uma mistura se configura, produzindo uma situação exclusiva.

Assim, cada narrativa construída está baseada em entendimentos prévios. Há,portanto, uma certa maneira de ler uma história e produzir um tipo de conhecimento. Falar em

6 "At best, history is a story about power, a story about those who won." (Tradução do autor).

7 "It contends that the historical narrative bypasses the issue of truth by virtue of its form. Narratives are necessarily emplotted in a way that life is not." (Tradução do autor).

8 "Historically specific groups of humans must decide if a particular narrative belongs to history or to fiction. In other words, the epistemological break between history and fiction is always expressed concretely through the historically situated evaluation of specific narratives." (Tradução do autor).

9 "Any historical narrative is a particular bundle of silences, the result of a unique process, and the operation required to deconstruct these silences will vary accordingly." (Tradução do autor). 
silêncio exige rever os fatos silenciados, não apenas revisitar arquivos, mas também a revisão do modo de interpretação destes dados.

Trouillot (2015) defende haverem pelo menos três estratégias principais de silêncio. A primeira ligada ao enterrar de determinadas histórias, a ausência dos fatos. $\mathrm{O}$ autor acredita que tanto presenças quanto ausências, na história, sejam criadas e não neutras ou naturais. E como tal, "não são meras presenças e ausências, mas menções ou silêncios de vários tipos e graus" "10 (Trouillot, 2015, p. 48). Assim como os fatos, os silêncios também são ativos, todos querem refletir algo. Inclusões e exclusões refletem escolhas, ambas são constitutivas do processo histórico.

Os silêncios são inerentes à história porque qualquer evento único entra na história faltando algumas das suas partes constitutivas.Algo é sempre excluído enquanto outra coisa é gravada. Não há um encerramento perfeito de um evento. Opta-se por definir os limites desse evento ${ }^{11}$ (Trouillot, 2015, p. 49).

O silêncio também pode acontecer pela forma de narrar uma história: pelo apagar de alguns fatos ou de sua relevância, ou ainda por sua banalização, esvaziam-se eventos, tornando-os triviais, adoça-se o ocorrido ou banaliza-se a unicidade da situação, focando-se nos detalhes. Mata-se um fato cancelando-o nas generalidades ou tornando-o irrelevante no acumular dos detalhes. Price (2016, p. 263) complementa que em muitos casos a diferença entre o que aconteceu e o que se diz ter acontecido revela uma "higienização"12 dos eventos para consumo público, isto é, “a criação de uma nova história para substituir aquela que foi excluída", visando não apenas silenciar narrativas indesejadas, mas também, ativamente criar outras que melhor contribuam para a mensagem que se pretende passar. Histórias que podem provocar uma sensação gratificante, responsável por gerar entusiasmo na audiência.

A segunda estratégia está ligada ao poder desigual dado para a produção de fontes, de arquivos e narrativas, capazes de gerar interpretações específicas. "Os silêncios deste tipo mostram os limites das estratégias que implicam uma reconstituição mais precisa do passado e, portanto, a produção de uma história 'melhor', simplesmente por um alargamento da base empírica"13 (Trouillot, 2015, p. 49). Nesta ótica, fontes são ignoradas

10 "They are not mere presences and absences, but mentions or silences of various kinds and degrees." (Tradução do autor).

11 "Silences are inherent in history because any single event enters history with some of its constituting parts missing. Something is always left out while something else is recorded.There is no perfect closure of any event, however one chooses to define the boundaries of that event." (Tradução do autor).

12 Para entender melhor a questão consultar: PRICE, Sally. Higienização da cultura: poder e produção de exposições museológicas. In: LIMA FILHO, M;ABREU, Regina; ATHIAS, Renato. Museus e Atores Sociais: perspectivas antropológicas. Recife: Aba Publicações, 2016.

13 "Silences of this kinds show the limits of strategies that imply a more accurate reconstitution of the past, and therefore the production of a 'better' history, simply by an enlargement of the empirical base." (Tradução do autor). 
e fatos não utilizados são tornados relevantes, tendo em vista ditar estratégias ou, ao menos, gerar restrições no campo de batalha pelo poder histórico. Alguns temas passam a ter seu espaço reduzido em favor de outros. "Eles terão direito à existência, à luz do campo, se forem constituídos por fatos criados anteriormente. Para fazerem sentido, será necessário destronar alguns fatos, apagar ou qualificar outros"14 (Trouillot, 2015, p. 49). Em consequência, tudo o que é escolhido reduz o espaço disponível para outros fatos.

Neste direcionamento, o uso comercial dos fatos históricos é um movimento interessante para dar credibilidade e reforçar uma narrativa em que ao mesmo tempo minimiza/banaliza forças dissidentes. Uma bandeira, um memorial, uma exibição museológica, ou mesmo uma comemoração se transformam em espetáculos vivos, com pretensões históricas e uma audiência diversa. Produtos mais diversificados possíveis, de uma batata frita até cigarros, são utilizados para expandir o conhecimento sobre determinada narrativa. Reforçam a materialidade, dão credibilidade. Ao mesmo tempo, silenciam aquilo que não é interessante ser visto.

$\mathrm{Na}$ terceira estratégia, os silêncios são produzidos nos interstícios do conflito entre intérpretes anteriores, isto é, não estão diretamente ligados a ausência de fatos ou no direcionamento das interpretações, mas sim nas dotações conflitantes.

Nos casos estudados algumas estratégias de silêncio podem ser observadas nos discursos e práticas oficiais. Em relação à primeira, através da forma de narrar uma história pelo apagar de fatos ou de sua relevância, ou ainda pelo esvaziamento de alguns eventos, tornando-os banais, é possível perceber como algumas questões centrais do processo histórico de Brumadinho e de Saint Louis são trabalhadas.

Em Inhotim, temas como a Comunidade de Inhotim, o passado de escravidão, as questões ambientais da cidade advindas com os anos de exploração pela mineração e os processos de gentrification ${ }^{15}$ são ora apagados ora banalizados.

No caso da Comunidade de Inhotim, esta é praticamente apagada pelo discurso oficial, como se Inhotim houvesse sido construído num vazio.

O Instituto Inhotim começou a ser idealizado pelo empresário mineiro Bernardo de Mello Paz a partir de meados da década de 1980. A propriedade privada se transformou com o tempo, tornando-se um lugar singular, com um dos mais relevantes acervos de arte contemporânea do mundo e uma coleção botânica que reúne espécies raras e de todo os continentes (Inhotim, 2016, on-line).

Um discurso oficial que pouco menciona sobre o passado, sobre o que ali havia antes da chegada do Instituto. Um vazio preenchido com e pelo parque.

14 "They will have the right to existence in light of the field constituted by previously created facts. They may dethrone some of these facts, erase or qualify other.” (Tradução do autor).

15 Lees et al (2008) definem gentrification como sendo a reconstrução das fronteiras da cidade, colocando-a sobre o interesse da elite e da classe média alta. Trata-se de processos de deslocamento, geralmente dos mais pobres, para outras regiões urbanas. 
A Comunidade de Inhotim localizava-se na zona rural do distrito de Conceição do Itaguá, município de Brumadinho-MG, a cerca de 50 quilômetros de Belo Horizonte, foi fundada em 1870 e abrigava, entre 1995 e 2005, cerca de 300 moradores com cerca de 70 moradias, e que, a partir de 2002, com a implantação, em terreno ao lado do da Comunidade, do Museu do Inhotim, e mais ainda com a expansão latifundiária da área expositiva do Museu, mediante a sistemática compra e ocupação de terrenos em seu entorno, aos poucos foram sendo levados a abandonar a região, após cerca de 140 anos de existência. Essa comunidade rural, originalmente formada principalmente por ex-escravos, cuja atividade de subsistência centrava-se em roçados e pequena criação, bem como na pesca e na caça para subsistência, era também atravessada por empreendimentos econômicos em escala industrial, seja os advindos da extração de minério (ouro, ferro, bauxita, malacacheta), seja aqueles relativos à existência de latifúndios (propriedade de empresa mineradora e, posteriormente, de empreendedores não ligados à mineração). Com a saída os últimos moradores, a Comunidade do Inhotim extinguiu-se. Essa extinção está intrinsecamente ligada à existência do Museu do Inhotim (Borges, 2015, p. 5-6).

No discurso oficial, pouco ou nada se encontra sobre o processo de destituição da comunidade, da diáspora dos moradores, de todo o processo de gentrification e desterritorialização ali existente. Tudo o que se depara, quando se localiza algo sobre, é referente a um processo pacífico de extinção da comunidade, com ganhos financeiros e sem perdas.

E é interessante que nessa relação da compra também é uma característica dele (Bernardo Paz), ele também é muito especial, ele não só compra, a gente tem cerca de 300 narrativas de vida e história com essas pessoas que moravam no povoado, [...] eles contam tanto das características desse processo de compra de que ele paga acima do mercado, ou o acordo dele com as pessoas é que escolhe onde você quer ir e eu compro (Entrevistado D). ${ }^{16}$

Em 2009 o Instituto ocupava integralmente a área. "Assim sendo, a comunidade de Inhotim é hoje um espaço geográfico que se projeta na extensão de uma memória que, embora esgarçada no tempo, reside no mais essencial dos imaginários” (Borges, 2015, p. 6).

Em consequência do processo de destituição da comunidade, apaga-se não apenas a tradição cultural outrora existente, mas igualmente os bens patrimoniais imóveis ali existentes. O boteco, o salão SãoVicente de Paulo, a escolinha municipal Santinha Maciel, o adro da Santa Cruz, o campinho de futebol. ${ }^{17}$ A extinta cultura local é invisibilizada.

O legado que fica é banalizado a partir de uma lembrança superficial, de maneira minimizada e distorcida. A casa da ex-escrava, na obra Continente/Nuvem, serve apenas

16 Mulher, por volta de 40 anos, gerente responsável pela relação social, Inhotim/Comunidade.

17 Como forma de resistência e buscando-se driblar o esquecimento, os moradores nativos contaram suas histórias tanto para Inhotim quanto para a mídia local (Borges, 2015). 
como suporte para a artista Rivane Neusenchwander. ${ }^{18}$ A igreja que a comunidade que ali vivia construiu, o cruzeiro e suas manifestações religiosas são mantidos, porém hoje, servem apenas para teatralizar elementos do passado ou mesmo do presente, servindo, inclusive, como espaço passível de ser alugado para eventos, como casamentos. As representações dos moradores da cidade e de sua cultura, presentes nas obras Abre a Porta e Rodoviária, são instrumentos utilizados para quebrar resistências da chegada de Inhotim a região.

Figura 1 - Imagens de obras de arte do Instituto Inhotim ${ }^{19}$
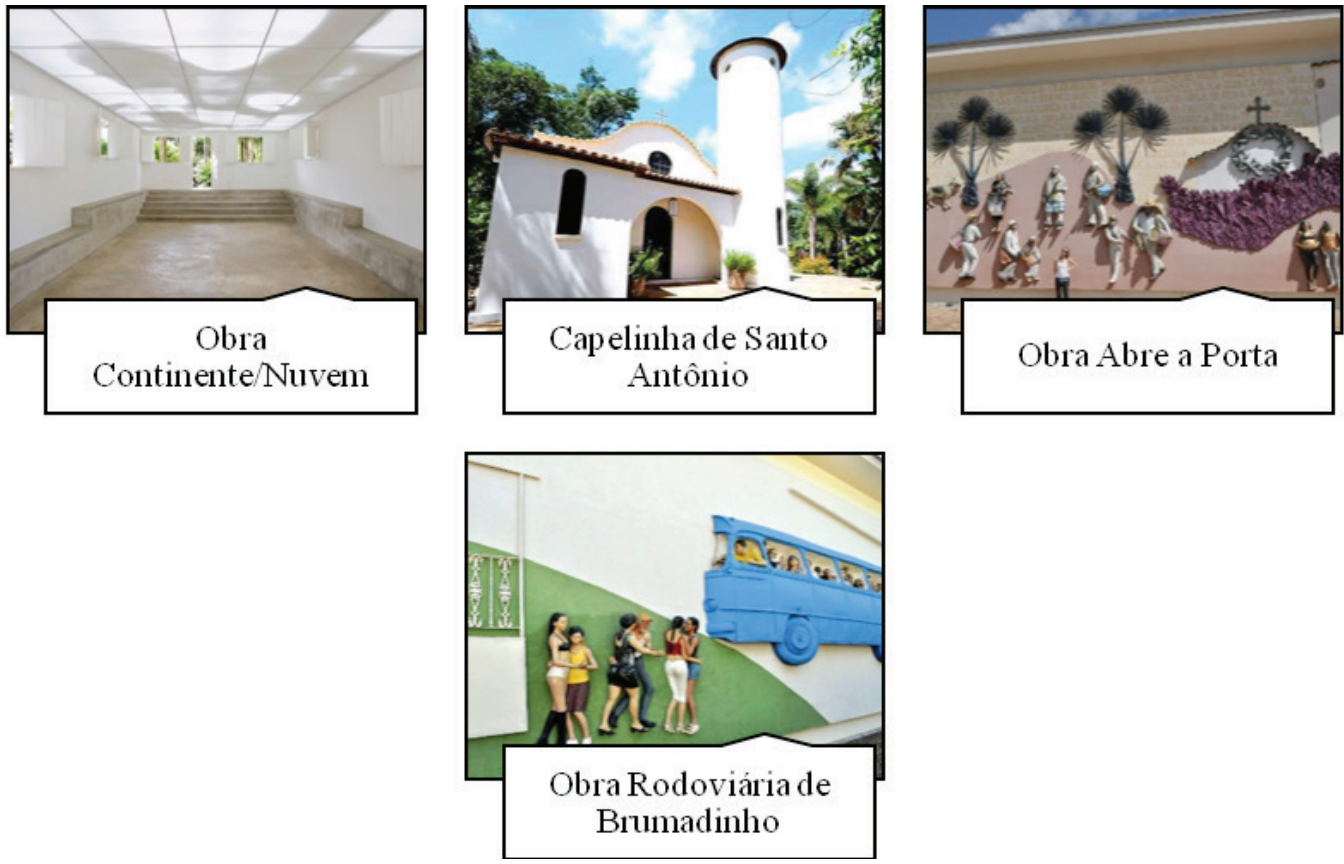

Utilizando-se de silêncios, Inhotim apresenta o passado do local como um ente sem nome e sem história. O referente original, a comunidade rural ali outrora existente, com seu complexo cultural, é eliminado do campo da história e das palavras. Omite-se os processos de violência simbólica e patrimonial. Mente-se sob a forma de verdade: embora o que esteja sendo contado seja verdadeiro, os motivos de dizê-lo não os são. A

18 Rivane Neuenschwander (Belo Horizonte, 1967) é uma artista plástica brasileira de respaldo internacional. Em Inhotim a artista expõe, desde 2008, a obra Continente/Nuvem. Esta obra está instalada em uma pequena casa de fazenda de 1874. Trata-se de uma obra cinética, que ocupa totalmente o teto da casa. Refere-se a pequenas bolas de isopor que se movem aleatoriamente sobre um forro transparente, criando formas abstratas monocromáticas, que aludem a mapas e ao movimento das nuvens do céu.

19 Fontes: Imagem “Obra Continente/ Nuvem” disponível em: < http://www.inhotim.org.br/blog/ inhotim-uma-trajetoria/>.Acesso em: 31 ago. 2016.; Imagem “Capelinha de Santo Antônio” disponível em: <http://imgsapp.impresso.em.com.br/app/da_impresso_130686904244/2014/01/26/104014/res20140124144055111049u.jpg>.Acesso em:04 out.2016.; Imagem “Obra Abre a Porta” disponível em: <http://4.bp.blogspot.com/-s8PzMY8BqGE/TbSP5ZBhKcI/AAAAAAAAAIU/awpUxt70k5o/ s1600/DSC_0056.JPG>. Acesso em: 02 ago. 2016.; Imagem “Obra Rodoviária de Brumadinho” disponível em: <http://3.bp.blogspot.com/-aSoObaxEM1Y/T8U0zTi0z4I/AAAAAAAAAmU/dFSpo4UJa6I/s1600/_DSC0533.JPG>.Acesso em: 26 set. 2016. 
antiga comunidade de Inhotim é dissolvida como condição necessária para a existência do Instituto.

Indubitavelmente, o empreendimento causou violência simbólica e patrimonial, considerando-se que a dinâmica do empreendimento-museu interferiu decididamente na paisagem local, modificando-a radicalmente; ação na qual se inclui, além da extinção física da Comunidade, a destruição patrimonial, seja por ação das máquinas (as propriedade adquiridas eram imediatamente destruídas a trator), seja pela ação discursiva, seja pelo encobrimento e esvaziamento da memória local (patrocinados tanto pelo empreendimento-museu como pela mídia).Desse modo, o empreendimentomuseu patrocinou a destruição de "vários bens [...] comunitários (bens materiais e imateriais) construídos em regime de mutirão ao longo dos anos antes da chegada do Museu (Borges, 2015, p. 8).

Outro elemento apagado é o passado de escravidão de Brumadinho. Não há, no discurso oficial, nenhuma menção sobre ele. Também como é possível considerar a escravidão, se não há passado em Inhotim? O passado oficial trata apenas das entradas e bandeiras, dos insubmissos que para lá se dirigiram, fugindo da repressão, a fim de garimpar ouro livre dos elevados tributos da Coroa. ${ }^{20}$ De um passado longínquo, chega-se diretamente a Inhotim, que vem para estabelecer relações multidimensionais com a cidade, ser agente propulsor do desenvolvimento social, educativo e cultural. A exploração econômica não é conveniente. Minimiza-se as relações de escravidão e o que isso significou para o legado das comunidades quilombolas e para toda a região. Nas poucas vezes que se faz algum contato com o passado, ele não aparece pela discussão do que representou e ainda representa. Não há empoderamento das comunidades locais. Há apenas uma memória superficializada, considerando-se, por exemplo, o legado musical e religioso herdado, trabalhado nos projetos culturais e sociais.

Um terceiro silêncio está ligado à questão do meio ambiente: as transformações ambientais que Inhotim provoca no local. A extensão latifundiária do complexo altera irrecuperavelmente a paisagem local, seus referenciais topográficos e afetivos, transformando tudo em algo irreconhecível, como aponta Gomes (2010, p. 16):

[...] da última vez que fui ao Inhotim confesso que me perdi um pouco. Como chegar ao sítio do [...]. Não sei mais, pois a expansão física do Museu do Inhotim ocupou tudo. Fiquei meio perdido porque a geografia dispersa que trago na memória da zona rural do Inhotim, ficou alterada. Passagens, estradinhas de barro, caminhadas na ribanceira dos rios e córregos, a lateral da ferrovia, os atalhos, etc. O não-lugar [...] dos que ali viveram por quase duzentos anos é uma realidade que ficou irreversivelmente alterada: a ambiência, os falres, as festas, tudo.

20 Lima Filho (2010) trata de situação análoga em alguns museus de Ouro Preto, Minas Gerais, Brasil. Em várias instituições culturais da cidade é possível observar uma invisibilização da herança cultural afro-brasileira/ouro-pretana. Para maiores detalhes ver: LIMA FILHO, M. Espelhos Patrimoniais: museus e passado afro-brasileiro. Revista Tomo, São Cristovão, SE, n. 16, p. 197-220, jan./jul. 2010. 
O silêncio é encobridor da paisagem. O visitante só consegue enxergar a realidade estetizada de Inhotim. Os vestígios que sobraram das pessoas, das coisas, dos hábitos culturais, foram esvaziados. Foram deslocados e ressignificados. Para o visitante, passam a ser apenas instalações. Mais uma dentre as tantas que se espalham pelo espaço museografado. "Não há história, há apenas arte" (Gomes, 2015, p. 13).

Uma história que Inhotim faz apagar-se pelo encantamento. Tudo o que resta é musealizado: as esculturas feitas a partir dos antigos moradores (Obra Abre a Porta e Rodoviária), os hábitos culturais, tal qual a dança fixada em escultura, a Capelinha de Santo Antônio, hoje esvaziada de seus paramentos religiosos, e uma casa rural, da exescrava.

O que ficou como vestígio são figuras sem historicidade, imobilizadas no tempo e no espaço e que foram moldadas no e pelo corpo de sujeitos históricos, hoje forcluídos da/pela mitogênese do Museu do Inhotim. A antiga Comunidade do Inhotim, agora transformada em deslugar, aparece, no Museu, na forma de sobra, de resto a digerir e que, de uma zona obscura da memória, provoca ruídos e certo incômodo na harmonia estetizante do Museu. Desse modo, na contramão de um lugar de memória, o Museu do Inhotim instala um lugar de silenciamento e esquecimento, um sítio de significância como cicatriz de uma excisão. [...] O objeto museal, como vestígio deslocado por meio da musealização, é investido de novos valores sendo, por isso, ressignificado (Borges, 2015, p. 14).

Fatos históricos são recontados a partir de outro olhar, revelando uma nova história. O silêncio está nos assuntos dos quais se quer desviar o olhar, na nova interpretação dada.

Outro silêncio que não é possível deixar de mencionar é o existente sobre o mantenedor de tudo isso: a mineração. Banaliza-se o fato de que a sustentabilidade dos encantos de Inhotim provenha da devastação e do vermelho do minério de ferro. O gozo da contemplação de belezas quer que se sobreponha a violenta exploração/corrosão socioecológica sem a qual Inhotim não poderia existir. $O$ investimento inicial para a criação do Instituto foi da ordem de 250 milhões de dólares. Sua manutenção advém principalmente dos investimentos feitos pelas empresas de Bernardo Paz, somados às receitas provenientes do dia a dia do Instituto e da captação de recursos. Mas isso é um tema que Inhotim quer fazer esquecer! Um fato sem importância, que deve ser higienizado para ganhar os moldes de um belo produto.

[...] é de desvincular a imagem do Bernardo como um mecenas, como um minerador mega milionário que criou Inhotim. A gente tem tentando trabalhar muito mais o Bernardo como um visionário, como um idealizador, muito mais do que esse homem cheio de dinheiro, magnata do minério que decide abrir um espaço e mais do que isso existe toda uma visão por trás, e é isso que a gente tenta trabalhar com relação a imagem dele e a presença (Entrevistado G). ${ }^{21}$ 
Por último, o silêncio também é encontrado no uso comercial das narrativas que se quer contar. "De produtos assinados por designers reconhecidos mundialmente a peças de cerâmica desenvolvidas por artesãos da região de Brumadinho" (Inhotim, 2016, online), Inhotim materializa a narrativa que quer contar. Ao mesmo tempo, age para reforçar, no silêncio, o que não lhe parece interessante evidenciar.

Quando chegaram/Trouxeram novos nomes, /Mas nós já tínhamos nome. //Quando chegaram/Trouxeram novas histórias, /Mas nós já tínhamos histórias. //Quando chegaram/Trouxeram novos projetos, /Mas nós já tínhamos projetos. //Quando saímos/ficaram com nossos projetos, /Nossos sonhos, /nosso nome, /e contaram outras histórias (Oliveira, 2010, p. 95).

No caso específico de Inhotim, discursos e práticas camuflam a dominação ideológica e econômica que se estabelece na região. O Instituto, fazendo uso do discurso do progresso, do "poder transformador do belo", isto é, do "poder da fruição" e da democracia impõe aos seus visitantes, mas, principalmente, aos moradores de Brumadinho e região sua visão de mundo. A ideologia do local é substituída pela ideologia do que vem de fora, do estrangeiro.

A proposta de aqui ser um local transformador, de ter uma proposta de um modelo de vida pós contemporâneo. [...] que esse local se transforme num modelo de vida mesmo para as pessoas que estejam aqui. Que esse local se transforme num local que as pessoas tenham acesso à cultura, meio ambiente, educação, inclusão, cidadania e que isso sirva de exemplo e que as pessoas queiram fazer parte disso. O principal é isso. Que todos queiram estar ali. Que queiram fazer parte deste modelo de vida que esse lugar propõe. Lógico que esse é um processo que com o tempo vai sendo construído. Mas é o grande objetivo (Entrevistado E). ${ }^{22}$

E como atua? Gradativamente Inhotim vai conquistando seu espaço, não pela imposição direta, pela força, mas pela sedução e pelo consenso, pela demonstração do que se pode obter com o progresso, com o novo, com o diferente, e como isso pode ter implicações positivas para a cidade. O sucesso derivado de um aparente ganha-ganha, somado a um discurso permeado pelo belo, é a forma pela qual Inhotim naturaliza seus interesses e impõe seus valores. Um aparente sucesso econômico melhora as condições de vida da região, passa a impressão de cuidado da Instituição com o lugar e favorece a continuação do projeto. A arte e o belo, num local acostumado à devastação e à destruição, encantam o olhar e distraem os focos. A democracia do acesso, as vozes com probabilidade de autoridade se ludibriam com a possibilidade, de pelo menos uma vez, serem escutadas.

E nesse sentido é mais fácil camuflar o significado velado da atuação de Inhotim em Brumadinho. No lugar da cidade, a invisibilidade de Brumadinho frente à grandiosidade de Inhotim. Brumadinho não aparece nem mesmo nos materiais publicitários do Instituto

22 Homem, cerca de 30 anos, responsável pelo atendimento aos visitantes. Mudou-se para Brumadinho em função do trabalho. 
(Faria, 2012). Obscurecessem-se os processos de gentrification, do desaparecimento gradual do local, do tradicional, entra a compensação financeira.

No caso do projeto Inhotim, utilizaram-se as ferramentas de mercado, ou seja, o preço de mercado da terra, com uma sobretaxa.A sociedade reconhece a vantagem financeira do negócio, embora com o passar do tempo o novo modo de vida se torne desconfortável. A extinção da Vila de Inhotim e os símbolos territoriais identificados pelas famílias que ali viveram serão uma memória, uma marca de um processo histórico neste território ${ }^{23}$ (Faria, 2012, p. 267).

Não mais os patrimônios culturais locais originais, mas os patrimônios ressignificados a partir do olhar de Inhotim. E neste ponto vale relembrar a posição de Nora (1993) sobre o museu como "lugar de memória", isto é, monumentos, instituições, rituais, entre outros, criados com o intuito de preservar uma memória oficial. Nesta perspectiva, as memórias são resultado de uma organização voluntária, intencional e seletiva. Não há memória espontânea. Há, sim, o salvaguardar de uma perspectiva que deixa de ser múltipla e coletiva e passa a se tornar única e sagrada.

E neste movimento, muitos objetos são deslocados. A eles são dados novos sentidos, dependendo da ocasião e dos interesses, produzindo significados e sentidos, nem sempre condizentes com o original.

[...] e nesse sentido eu acho que o Instituto é mito contemporâneo porque ele pega a cena que o Moçambique faz, que é uma tradição, que aqui é muito católico, que é o catolicismo, mas africanamente, transforma essa cena na obra que está na Galeria Praça, né (Entrevistado D).24

E qual a finalidade da ressignificação de objetos? O ressignificar permite que os sujeitos "percebam e experimentem subjetivamente suas posições e identidades como algo tão real e concreto quanto os objetos que os simbolizam" (Gonçalves, 2007, p. 21).

No caso de Inhotim, o ressignificar tem finalidade específica: trazer à tona um novo discurso, reestruturado a partir dos interesses e da força da institucionalização que Inhotim provoca. Vejamos o caso da obra Continente/Nuvem, de Rivane Neusenchwander (Figura 1). A casa onde a obra está era de uma antiga moradora da região, escrava, que ao ser alforriada, a ganhou do proprietário da terra. Em qual elemento da obra encontramos as discussões sobre a escravidão na região e, especificamente, as situações que ocorreram nas terras de Inhotim quando da extinção da Vila Inhotim? Por que somente a fachada externa da antiga casinha é preservada e internamente tudo é modificado para atender

23 "En el caso del proyecto de Inhotim, se utilizaron las herramientas de mercado, es decir, el precio de mercado de las tierras, con un sobreprecio. La sociedad reconocen la ventaja financiera del negocio, aunque con el paso del tiempo el nuevo modo de vida se vuelve incómodo. La extinción de laVila de Inhotim y de los símbolos territoriales identificados por las familias que ahí vivían será un recuerdo, una marca de un proceso histórico en este territorio.”(Tradução do autor).

24 Mulher, por volta de 40 anos, gerente responsável pela relação social, Inhotim/Comunidade. 
aos interesses do artista? Por que os processos de gentrification não são mencionados? Por que Inhotim silencia e ressignifica aspectos presentes em seu próprio território?

A história é relatada sob um contexto específico. O passado de Brumadinho é recuperado e recontado a partir do olhar de Inhotim. O mesmo pode ser dito sobre o passado recente da cidade e sua relação com a mineração. Os temas cotidianos vivenciados em Brumadinho são pouco explorados por Inhotim. Analisado sobre a opinião de Trouillot (2015), o que acontece é a existência de silêncios nas narrativas históricas. Eventos e fatos são recuperados, sujeitos a evidenciações e interpretações de forma a assumirem uma certa maneira de ler a história e produzir um tipo de conhecimento.

$\mathrm{Na}$ opinião de Carvalho (2004), ao atuar desse modo, Inhotim exerce uma atitude de impunidade estética. Mais do que uma questão de ressignificação de símbolos tradicionais, refere-se a um modo de expropriação de tradições e exercício inusitado do poder.

$\mathrm{O}$ que se vê, portanto, é que Inhotim usa seu discurso institucionalizado para construir uma imagem do Instituto como um local de geração de conhecimento, mas omite seu poder disciplinador, que define as histórias e os valores a serem repassados a partir das obras e projetos. Tal situação também pode ser comprovada a partir de outro elemento: o modo de trabalho da curadoria. O trecho abaixo esclarece.

Nós temos um contexto, uma forma muito específica de trabalhar, convidamos artistas para fazerem trabalhos específicos pra Inhotim ou para trazerem trabalhos que nós, trabalhos anteriores, que nós vamos criar todo um contexto novo para recebê-lo. [...]. Nós tentamos o melhor possível para não subverter os trabalhos. Os artistas são sempre informados. Os artistas participam sempre (Entrevistado I). ${ }^{25}$

Os valores são pensados e expostos tanto na forma de arte quanto na construção da beleza natural. "Então dificilmente uma galeria vai estar ali e eles vão fazer um tipo de paisagismo porque fizeram, porque é bonitinho! Eles tentam envolver a arte e a botânica juntamente" (Entrevistada B). ${ }^{26}$

O museu, assim, se constitui num espaço de lembranças e esquecimentos, onde os objetos revelam e ocultam determinados sentidos sobre o passado."Não apenas demarcam ou expressam posições, mas organizam ou constituem o modo como indivíduos e os grupos sociais experimentam subjetivamente suas identidades e status" (Gonçalves, 2007, p. 21), fazem parte de sistemas simbólicos, de categorias culturais construídas, que tem a função não apenas de representar, mas de organizar e constituir a vida social: delimitam contextos, permitindo entender a própria dinâmica da vida social ali existente.

O caso de Saint Louis Art Museum - SLAM - não é tão diferente. No SLAM silêncios também existem. Um silêncio que vai se dar principalmente no tocante à questão racial. Da parte de Saint Louis, os conflitos advindos dos processos de escravidão e ainda as tensões raciais, são silêncios marcantes, apesar de haver uma retomada dos

25 Mulher, cerca de 35 anos, funcionária, área de Curadoria Artística.

26 Mulher, cerca de 35 anos, psicóloga, responsável pelo recrutamento e treinamento de funcionários. 
conflitos na cidade, como o caso de Ferguson, ${ }^{27}$ e do tema ser uma agenda marcante nos Estados Unidos nos últimos anos. "A América de Barack Obama ainda é extremamente segregada - não por lei, mas por escolha individual e faixa de renda"28 (Mount, 2010, não paginado). Pelo site do museu, por exemplo, é possível visualizar que de 2010 a 2016 , das 87 exposições temporárias ocorridas, apenas uma tratou de assunto ligado à questão afro-americana. Na figura abaixo é possível encontrar detalhes.

Figura 2 - Anything but Civil: Kara Walker's Vision of the Old South

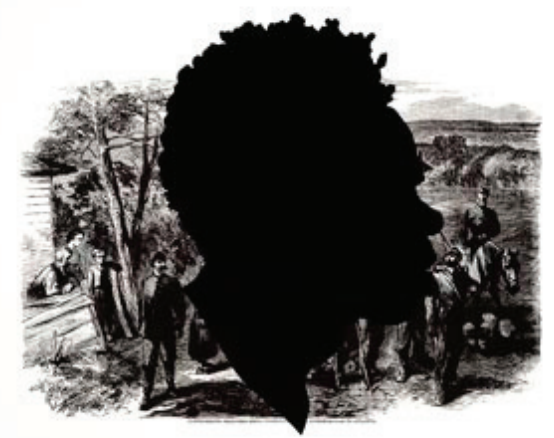

Anything but Civil: Kara Walker's Vision of the Old South

February 26 - August 10, 2014

Galleries 234 and 235

Fonte: Disponível em: <http://www.SLAM.org/Exhibitions/archive/anythingbutcivil.php>. Acesso em: 05 out. 2016.

O mesmo acontece com os projetos educativos e sociais desenvolvidos pelo Saint Louis Art Museum. Apenas um projeto, $A$ world of diference, ${ }^{29}$ de todos os 33 desenvolvidos no ano de 2015, explora o tema sobre diferenças raciais, buscando prover um contexto para que os alunos discutam as percepções individuais e tentam interromper o viés e o preconceito. Isso, no entanto, não implica, necessariamente, que o tema seja abordado.

A coleção principal e permanente também revela outro silêncio sobre o mesmo assunto. Ao todo são 33 mil peças disponíveis no museu. Deste total, as obras da cultura afro-americana representam um percentual mínimo. A única menção encontrada no site institucional sobre este tipo de obra é retratada abaixo:

O Museu de Arte de Saint Louis está empenhado em colecionar e exibir obras importantes de artistas afro-americanos. Nossas explorações incluem

27 Para mais informações sobre o caso de Ferguson ver: <http://www.dw.com/pt-br/entenda-o-caso-michael-brown-e-os-protestos-em-ferguson/a-17861142>. Acesso em: 02 nov. 2016.

28 Barack Obama's America is still extremely segregated - not by law, but by individual choice and income bracket (Tradução do autor). Material disponível em: MOUNT, Harry. Post-racial America? Forget it. The Spectator, Londres, 25 set. 2010.

29 Um mundo de diferenças (Tradução do autor). 
artesanato, pinturas, escultura, têxteis, fotografias, desenhos e estampa datados do início do século XIX até hoje.Em 1943, o Museu recebeu um presente de 60 pinturas, gravuras e desenhos criados sob os auspícios do Projeto de Arte Federal, e essa aquisição proporcionou uma base significativa do trabalho do século XX. Entre os artistas representados na coleção estão Peter Bentzon, Henry Ossawa Tanner, Edmonia Lewis, James Van Der Zee, Charles White, Archibald Motley, Romare Bearden, Jacob Lawrence, Moneta Sleet, Faith Ringgold, Kara Walker e Julie Mehretu ${ }^{30}$ (Slam, 2016, on-line).

$\mathrm{Na}$ coleção que pode ser pesquisada on-line, das 2.900 peças disponibilizadas, apenas 93 são catalogadas como arte afro-americana. No livro "Saint Louis Art Museum Handbook of the Collection" (2004), que descreve peças da coleção do museu, não há qualquer menção a arte afro-americana. A impressão que se tem é que a cultura afroamericana é tratada como algo menor, secundária, em que se dá menor mérito. Um assunto ao qual não se dá importância e relevância. Banal. O trecho abaixo esclarece o foco das obras do museu nos seus 125 anos:

Nos últimos 125 anos, as compras do museu representam a maioria das obras de arte nas coleções de pinturas e escultura asiáticas, arte européia antes do século XIX e arte americana antes do meio do século XX. Presentes e legados de coleções formados em St. Louis deram forma dramática às explorações do museu nos têxteis do Near Eastern, porcelanas e bronzes chineses, mestres antigos e estampas e desenhos modernos, arte africana, oceânica e pré-colombiana e pintura européia e americana e escultura das eras modernas e contemporâneas $^{31}$ (Benjamin, 2004, p. 16).

Outra questão relacionada ao silêncio das obras afro-americanas está ligada ao tipo de curadoria que se estabelece e o público. Além das poucas obras selecionadas, o museu faz uma seleção de peças, dando seu parâmetro do que seja qualidade para este tipo de trabalho. Uma versão que as audiências afro-americanas não entendem como sendo representativa de sua identidade.

30 "The Saint Louis Art Museum is committed to collecting and displaying important works by African American artists. Our holdings include silverwork, paintings, sculpture, textiles, photographs, drawings, and prints dating from the early 19th century to present day. In 1943, the Museum received a gift of 60 paintings, prints, and drawings created under the auspices of the Federal Art Project, and this acquisition provided a significant base of 20th-century work. Among the artists represented in the collection are Peter Bentzon, Henry Ossawa Tanner, Edmonia Lewis, James Van Der Zee, Charles White, Archibald Motley, Romare Bearden, Jacob Lawrence, Moneta Sleet, Faith Ringgold, Kara Walker, and Julie Mehretu." (Tradução do autor).

31 "Over the past 125 years Museum purchases account for the majority of works of art in the collections of Asian paintings and sculpture, European art before the mid-nineteenth century, and American art before the mid-twentieth century. Gifts and bequests of collections formed in St. Louis have dramatically shaped the Museum's holdings of Near Eastern textiles, Chinese porcelains and bronzes, old master and modern prints and drawings, African, Oceanic, and Pre-Columbian art, and European and American painting and sculpture of the modern and contemporary eras." (Tradução do autor). 
[...] é dificil porque você não vê alguém que se parece com você, você não vê arte que reflita sua cultura, você não está lá. Mas os museus não foram construídos... Eles foram construídos a partir de um ponto de vista europeu. Então, bom, você está tentando impor uma estrutura multicultural em cima de $\operatorname{algo}^{32}$ (Entrevistado K). ${ }^{33}$

Um terceiro silêncio pode ser encontrado em relação ao poder desigual para produção de fontes documentais. Na categoria African-American Art só existe um curador associado. As categorias mais relevantes, no entanto, possuem curador direcionado, como é o caso da American Art.

O poder desigual na produção de fontes documentais pode ser observado em outro elemento. De toda a diretoria do museu entrevistada, apenas uma pessoa é afroamericana, a diretora para novas audiências, contratada exclusivamente para tornar o museu menos elitista, mais inclusivo e próximo dos diversos grupos sociais que compõem a população americana, principalmente os afro-americanos. A diretora, no entanto, expõe suas dificuldades.

Então eu disse isso para dizer que, com a minha posição, entrei e visava especificamente a comunidade afro-americana. [...] Acho que a parte mais dificil é o compromisso institucional. Penso que muitas vezes, instituições em todo os Estados Unidos, não apenas o Museu de Arte de Saint Louis, eles querem dar essa responsabilidade a uma pessoa da equipe. E não é uma questão pessoal. Se você está olhando para diversificar sua audiência, para estudar seu público, você precisa ampliar todos os aspectos do que você faz. De suas exposições especiais para sua coleção permanente, para sua equipe, para sua programação, para absolutamente tudo o que você faz em seu prédio $^{34}$ (Entrevistado K). ${ }^{35}$

Por último, não é possível deixar de mencionar os produtos comercializados pelo museu, e sua tendência a reproduzir ali apenas as principais coleções. Uma busca on-line por produtos de arte afro-americanos resulta em uma página vazia.

32 “...] it's difficult because you don't see someone who looks like you, you don't see art that reflects your culture, you won't be there. But museums weren't built. They we're built from a European point. So, nice you're trying to impose a multicultural structure on top of something." (Tradução do autor).

33 Mulher, afro-americana, cerca de 45 anos, Diretora para Desenvolvimento de Audiências.

34 "So I said that to say that with my position I came in and specifically target at the African American community. [...] I think the hardest part is the institutional committing. I think that too often, institutions across the US, not just the Saint Louis Art Museum, they wanna give that responsibility to a staff person. And it's not a single staff person. If you're looking at diversifying your audience, of broading your audience, you need to broad every aspect of what you do. From your special exhibitions to your permanent collection, to your staffing, to your programing, to absolutely everything you do in your building." (Tradução do autor).

35 Mulher, afro-americana, cerca de 45 anos, Diretora para Desenvolvimento de Audiência. 
Figura 3 - Busca por produtos de arte afro-americanos na loja on-line do SLAM

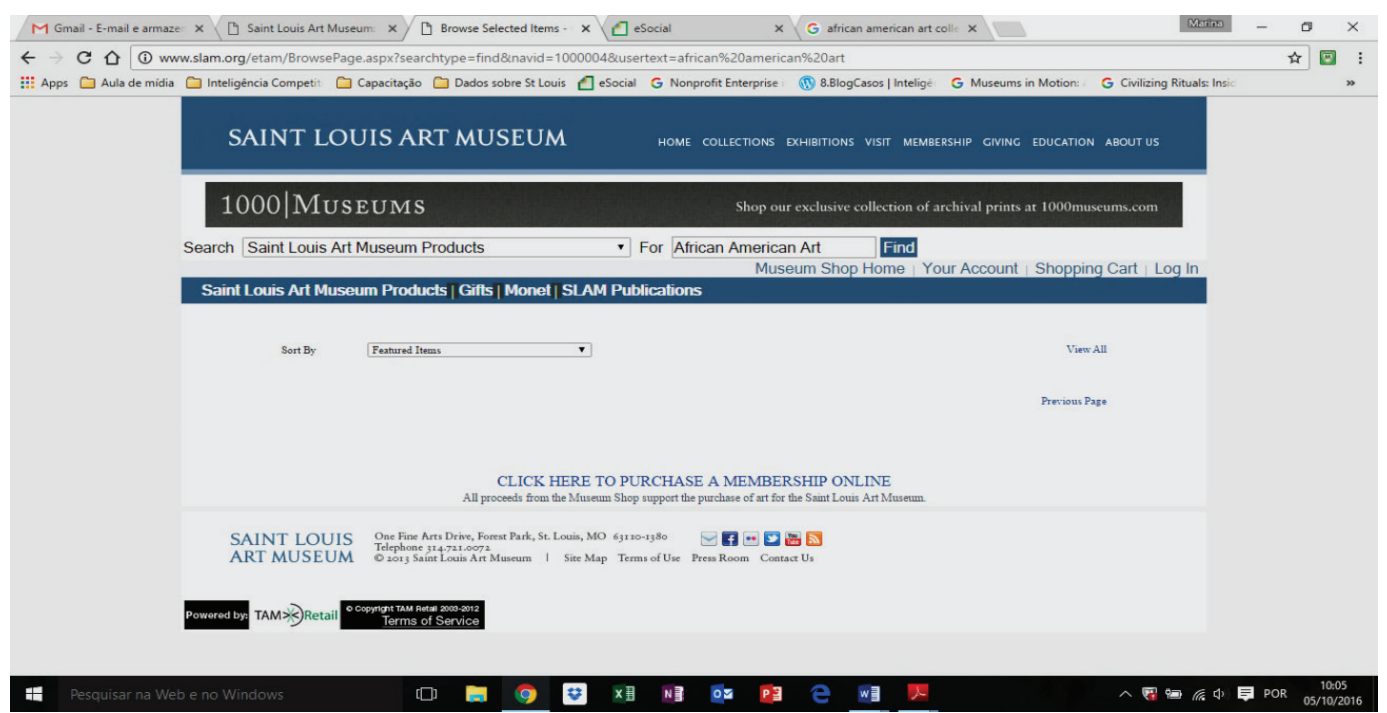

Fonte: Imagem disponível em: <http://www.SLAM.org/etam/BrowsePage.aspx?searchtype=find\&navid=1000004\&usertext=african\%20american\%20art>. Acesso em: 05 out. 2016.

O que se tira, portanto, do que foi demonstrado até aqui é que também no caso do Saint Louis Art Museum, existem silêncios estratégicos. O silêncio sobre o passado escravagista e a ausência de discussões sobre o presente repleto de disputas raciais. Constróise uma identidade higienizada da população afro-americana, uma versão que pode ser consumida pelo público, em que se reforça a supremacia branca e o pacto de harmonia estabelecido pelas elites no passado. Ao público afro-americano cabe apenas estar sujeito às táticas de marketing e captação de novas audiências, visando o financiamento do museu.

$\mathrm{O}$ que acontece no Saint Louis Art Museum não é um caso exclusivo. Ao analisar o caso do Colonial Williamsburg ${ }^{36}$ é possível encontrar situação parecida. Seus dados são de grande valia para explicar o que acontece no SLAM. Segundo Handler e Gable (1997), a história americana, até a década de 1970, focava muito nos grandes homens e na elite, ignorando o trabalho e a vida da vasta maioria da população. Também estava direcionado quase exclusivamente para as celebrações, privilegiando o consenso nacional e ignorando os conflitos sociais, os processos de luta, opressão, exploração e injustiça que ali existiram. Só após momentos marcantes na vida americana, como a Guerra do Vietnã, Watergate e os Civil Rights Moviments é que o público se tornou mais consciente sobre a velha história

36 Colonial Williamsburg é um museu de história viva e uma fundação privada localizada no distrito histórico da cidade de Williamsburg, na Virgínia, Estados Unidos. Suas instalações incluem prédios do século XVIII, do período em que a cidade era a capital da Virginia Colonial, do século XVII e também XIX. Foi fundado no final de 1920 pelo Reverendo Dr.W.A. R. Goodwin, um dos líderes da comunidade, juntamente com organizações que buscavam a preservação do passado da região. Trata-se de uma interpretação da vida nos tempos da cidade colonial americana. Para mais informações acessar: <http://www.williamsburg.org/> Acesso em: 06 out. 2016; LIMA FILHO, Manuel Ferreira. Paisagens patrimoniais e o jogo do tempo em Williamsburg (EUA) e Ouro Preto (Brasil). In: SILVEIRA, Flávio L. A. da; CANCELA, Cristina D. (Org.). Paisagem e Cultura - dinâmicas do patrimônio e de memória na atualidade. Belém: EDUFPA, 2009. 
do consenso e da celebração presente nos museus. A partir deste momento, uma nova história social é criada para reparar o equilíbrio. Neste novo momento, Williamsburg, por exemplo, continuaria a celebrar a identidade e a comunidade americana, mas não mais faria silêncio sobre as injustiças passadas e suas ramificações no presente. "Em suma, o passado que a história social deveria introduzir no museu é a de um passado mais sujo, tanto literal como metaforicamente" 37 (Handler; Gable, 1997, p. 4). Uma outra história mais profunda começava a ser contada. Uma visão construtivista dos fatos. Um desafio ao autoritarismo objetivo da história nos museus norte-americanos.

Mas contar uma nova história implica enfrentar a resistência dos patrocinadores, isto é, das instituições que representam os valores hegemônicos, valores congênitos da elite que estabelece, funda e administra as principais instituições culturais do país. Ao mesmo tempo corresponde a desafiar a própria estrutura institucional, que após a Segunda Guerra Mundial, se torna cada vez mais híbrida, posicionada entre o trabalho cultural, de um lado, e como negócio de outro. Uma complexa rotina que opera na fronteira entre o entretenimento de massa e sua educação.

Uma estrutura que depende do atendimento do desejo da audiência, e em que qualquer revisão histórica, precisa ser compatível com a viabilidade financeira. Dados de monitoramento de audiências, o formato pelo qual consomem produtos históricos, têm sido utilizados para recondicionar produtos culturais de acordo com as necessidades e desejos dos consumidores. O SLAM, há mais de décadas monitora seus frequentadores! (Inhotim também faz monitoramento semelhante). Está atento às necessidades e desejos de suas audiências. Vive-se uma era produtor-produto-consumidor, em que todos estão conscientes da intenção dos produtores.

Desta forma, vive-se sim um momento em que as revisões estão preocupadas em incluir o que antes havia sido excluído. No caso de Williamsburg, a escravidão, a sujeira do cocô dos cavalos, etc. No caso do Saint Louis Art Museum, algumas peças da arte afro-americana. No caso de Inhotim, a percepção da população local. Uma nova história que vai buscar na inclusão de paradigmas justapostos a comprovação de sua autenticidade. Ícones opostos passarão a representar algo entre a história crítica e a história celebrativa, o passado sujo e o passado ao estilo Disney, a velha e a nova história. Mas é na autenticidade que é possível encontrar sua principal vulnerabilidade: é na busca por criar e manter a aparência correta, que quer se estabelecer como verdade, que se encontram as maiores inverdades. "Um mundo corporativo, planejado, ordenado, arrumado, sem sujeira, sem cheiro, sem sinais visíveis de exploração"38 (Handler; Gable, 1997, p. 59).

Desta forma, os museus não podem ser vistos como simples repositórios culturais e de tesouros históricos. São, sim, arenas em que há a convergência de forças políticas e culturais. Museus produzem mensagens e ações cotidianamente. Mensagens sujeitas a

37 "In short, the past that social history introduced into the museum was to be a dirtier past, both literally and metaphorically." (Tradução do autor).

38 "A corporate world, planned, orderly, tidy, with no dirt, no smell, no visible signs of exploitation." (Tradução do autor). 
regras próprias: a história repassada ao público depende das regras impostas pelos museus, isto é, seus valores e expectativas, ao mesmo tempo em que estão condicionadas às regras que os visitantes trazem.

No caso de Saint Louis é possível perceber que o silêncio sobre a situação afroamericana está devidamente alinhado ao pensamento da elite branca da cidade, ao pacto de harmonia ali existente. Um museu que é gratuito para todos, que se diz de portas abertas para todos que o querem frequentar, mas onde as diferentes culturas não conseguem encontrar sua representatividade cultural.

Estes aspectos mencionados agem não simplesmente como forças que se impõem aos profissionais dos museus, de seu exterior, mas trata-se de elementos que estas pessoas precisam internalizar largamente.

Ou, por outras palavras, a conversa habitual do insider sobre esses fatos sociais é um fato social por direito próprio e crucial, pois suas decisões e ações são influenciadas pela forma como antecipam os impactos do conservadorismo e comercialização de classes $^{39}$ (Handler; Gable, 1997, p. 24).

O que se tem, portanto, é que a história recontada nos museus é um constructo, uma seleção de aspectos do passado, desenhadas a partir de lições morais e políticas, direcionadas pelas preocupações da época e das agendas que se estabelecem. "No trabalho diário do museu, a visão construcionista da história é amplamente superada e obscurecida pela noção de que a história é uma simples contabilização de fatos, e isso, por sua vez, corro e a mensagem da nova história social"40 (Handler; Gable, 1997, p. 78).

Retomando os casos estudados, o que se percebe é que as histórias são apresentadas como ideologicamente neutras. Mas, como visto, não o são. Analisado sob a ótica de Price (2016), o que ocorre em Inhotim e no SLAM é a higienização daquilo que não é agradável, do que não precisa ser visto. Opta-se por não reacender memórias de acontecimentoschave do passado. No máximo, faz-se uma cobertura superficial das questões.

Desta maneira, o que não se adéqua a ideologia dominante é silenciado. Conteúdos são excluídos, marginalizados e com o passar dos anos, esquecidos, sobrevivendo, em alguns casos, apenas na história oral de grupos determinados. No caso específico das instituições analisadas, o silêncio tem função própria: promover a acomodação do meio social. É a partir do enquadramento da memória que se busca manter a coesão interna e defender as fronteiras que se quer estabelecer. O que se institui é o sentido de identidade individual e de grupo.

39 "Or to put it another way, the insider's habitual talk about those social facts is a social fact in its own right, and a crucial one, for their decisions and actions are influenced by the way they anticipate the impingements of class conservatism and commercialization." (Tradução do autor).

40 "In the daily workings of the museum, the constructionist view of history is largely overcome and obscured by a notion that history is a simple accounting of just the facts, and that this, in turn, erodes the message of the new social history." (Tradução do autor). 
O trabalho de enquadramento da memória se alimenta do material fornecido pela história. Esse material pode sem dúvidas ser interpretado e combinado a um sem-número de referências associadas, guiado pela preocupação não apenas de manter as fronteiras sociais, mas também de modifica-las, esse trabalho reinterpreta incessantemente o passado em função dos combates do presente e do futuro (Pollak, 1989, p. 8).

Em Inhotim, o Instituto precisa fazer Brumadinho reinventar sua própria história:uma nova relação com seu passado, com o meio ambiente, com a mineração, com a devastação. Já Saint Louis Art Museum opta por omitir, por excluir aquilo que não lhe convém. Minimiza, banaliza o que não considera relevante. Evitar trazer à tona as desarmonias existentes. Nos dois casos as instituições reforçam sua posição de autoridade. "Mas para estabelecer o julgamento de alguém como autoritário, sua base de especialização deve ser evidenciada e sua conexão com os valores pessoais minimizados" 41 (Handler; Gable, 1997 , p. 33).

Uma reinterpretação da história que ocorre a partir das testemunhas que são oficialmente autorizadas a divulgar a memória oficial, ao mesmo tempo em que atua pelos acontecimentos e personagens específicos, que estabelecem pontos de referência, solidificando uma determinada memória.

O passado é, portanto, reinterpretado com finalidade bastante específica, atender aos combates do presente e do futuro, e servindo como ingrediente importante para a garantia da perenidade do tecido social e das estruturas institucionais. Atuam sob determinada conjuntura, intervindo na definição do consenso social e dos conflitos.

\section{Referências}

BENBENASTE, Narciso. La irracionalidad en la dinámica económica y de la política. Hologramática, Facultad de Ciencias Sociales - UNLZ, México, ano III, v. 3, n. 5, p. 63-73, 2006.

BENJAMIM, Brent et al. Saint Louis Art Museum - Handbook of the Collection. Itália: Conti Tipocolor, 2004.

BORGES, Luiz Carlos. O Inhotim que o outro Inhotim engoliu: museu, silêncio e transfiguração de memórias. In: XVI ENCONTRO NACIONAL DE PESQUISA EM CIÊNCIA DA INFORMAÇÃO, 2015, João Pessoa. João Pessoa: Universidade Federal da Paraíba. Disponível em: <http://www.ufpb.br/evento/lti/ocs/index.php/ enancib2015/enancib2015/paper/viewFile/2734/1202>.Acesso em: 04 out. 2016.

CANCLINI, Néstor García. Culturas Híbridas. São Paulo: Editora Universidade de São Paulo, 2008.

CARVALHO, José Jorge. Metamorfoses das tradições performáticas afro-brasileiras: de patrimônio cultural a indústria de entretenimento. Brasília: Série Antropológicas, 2004. Disponível em: < http://www.cachuera.org.br/cachuerav02/ images/stories/arquivos_pdf/serie354empdf.pdf>.Acesso em: 03 out. 2016.

DOUGLAS, Mary. Como as instituições pensam. São Paulo: Editora da Universidade de São Paulo, 1998.

FAIR CLOUGH, Norman. Discurso e mudança social. Brasília: Universidade de Brasília, 2001.

41 "But to establish one's judgment as authoritative, their basis in expertise must be stressed and their connection to what are ultimately personal values downplayed." (Tradução do autor). 
FARIA, Diomira Maria Cicci Pinto. Análisis de la capacidad del turismo en el desarrollo económico regional: el caso de Inhotim y Brumadinho. 2012.364 f. Tese (Doutorado em Economia) - Facultad de Económicas/ Faculdade de Ciências Econômicas, Universidade de Alicante/ Universidade Federal de Minas Gerais, Alicante, 2012.

FOUCALT, Michel. Vigiar e Punir. 1999. Disponível em: <https://comunicacaodasartesdocorpo.files.wordpress. com/2013/11/foucault-michel-vigiar-e-punir.pdf>. Acesso em: 23 mar. 2016.

GOMES, Alexandre; OLIVEIRA, Ana Amélia. A construção social da memória e o processo de ressignificação dos objetos no espaço museológico. Revista Museologia e Patrimônio, v. 3, n. 2, p. 42-55, jul./dez. 2010. Disponível em: <http://revistamuseologiaepatrimonio.mast.br/index.php/ppgpmus/article/viewFile/136/134>. Acesso em: 29 set. 2016.

GOMES, João de Lima. Apresentação: um peixe na árvore. In: OLIVEIRA,Valdir de Castro. Réquiem pelo Inhotim. São Paulo: All Print, 2010. p. 13-19.

GONÇALVES, José Reginaldo Santos. Antropologia dos objetos: Coleções, Museus, Patrimônios. Rio de Janeiro: Editora Garamond, 2007. (Coleção Museu, Memória e Cidadania).

HANDLER, Richard; GABLE, Eric. The new history in an old museum: creating the past at Colonial Williamsburg. Durham: London: Duke University Press, 1997.

INHOTIM. Disponível em: <www.inhotim.org.br>. Acesso em: 26 jan. 2016.

LEES, Loretta et al. Gentrification. New York: Routledge, 2008.

MARCHIORI, Marlene et al. Reflexividade no Discurso das Organizações: um espaço crítico de interação e diálogo. In: Congresso Brasileiro Científico de Comunicação Organizacional e de Relações Públicas - Abrapcorp, 3, 2009, São Paulo, SP. Anais... São Paulo: Abrapcorp, 2009. Disponível em: < http://www.abrapcorp.org.br/ anais2009>. Acesso em: 21 maio 2018.

MARCUSE, Herbert. Cultura e Sociedade. Rio de Janeiro: Paz e Terra, 1997. (v. I e II).

MOUNT, Harry. Post-racial America? Forget it. The Spectator, Londres, 25 set. 2010. Disponível em: <https:// www.spectator.co.uk/2010/09/postracial-america-forget-it/>. Acesso em: 28 ago. 2017.

NORA, Pierre. Entre história e memória. A problemática dos lugares. Projeto História, São Paulo: PUC, v. 10, n. 10, p. 7-28, dez. 1993.

OLIVEIRA,Valdir de Castro. Réquiem pelo Inhotim. São Paulo: All Print, 2010.

POLLACK, Michael. Memória, esquecimento, silêncio. Estudos Históricos, Rio de Janeiro, v. 2, n. 3, p. 3-15, 1989. Disponível em: <http://www.uel.br/cch/cdph/arqtxt/Memoria_esquecimento_silencio.pdf>. Acesso em: 16 set. 2016.

PRICE, Sally. Higienização da cultura: poder e produção de exposições museológicas. In: LIMA FILHO, Manuel; ABREU, Regina; ATHIAS, Renato. Museus e atores sociais: perspectivas antropológicas. Recife: Editora Universitária UFPE: Aba Publicações, 2016. p. 263-283.

SLAM - Saint Louis Art Museum. Disponível em: <www.slam.org>. Acesso em: 08 mar. 2016.

TROUILLOT, Michel-Rolph. Silencing the past. Beacon Press. 2015. Disponível em: < https://books.google.com.

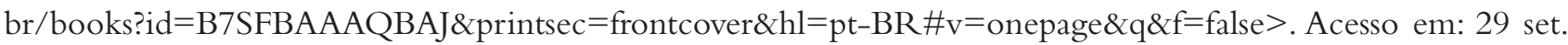
2016. 


\title{
Collections, silences, hygiene and class hegemony - an analysis of the cases of Inhotim (Brazil) and Saint Louis Art Museum (USA)
}

\begin{abstract}
In the contemporary context, many art museums move towards structuring themselves with a focus on the logic of the market and the demands of a globalized economy, leading to more inclusive, dialogical, technological practices focused on audience volumes. However, in looking at the exhibited collections in these institutions, it is possible to observe that, despite a supposed democratic opening, these objects tend to be indexed in specific referents, and in many cases, undergo processes of silence and hygiene, reinforcing the unequal relationship between who shows and who is shown. To better understand this situation, this article focuses on the analysis of two cases, the Inhotim Institute (Brazil) and the Saint Louis Art Museum (USA). It seeks to understand the role of the collections present, in order to show, from the relationship between researchers and interlocutors, the networks and positions that are constituted.
\end{abstract}

Keywords: Democratic openness, collections, hygiene, silences, class hegemony.

\section{Colecciones, silencios, higienización y hegemonía de clases - un análisis sobre los casos de Inhotim (Brasil) y Saint Louis Art Museum (EEUU)}

\section{Resumen}

En el contexto contemporáneo, muchos museos de arte son orientados para estructurarse con foco en la lógica del mercado y en las demandas de una economía globalizada, ocasionando prácticas más inclusivas, dialógicas, tecnológicas, concentradas en volúmenes de audiencia. Sin embargo, al mirar a las colecciones expuestas en estas instituciones, es posible observar que, a pesar de una supuesta apertura democrática, estos objetos tienden a ser indexados en referentes específicos, y en muchos casos, sufrir procesos de silencio e higienización, reforzando la relación desigual entre quien muestra y quien es mostrado. Para entender mejor esta situación, este artículo se centra en el análisis de dos casos, el Instituto Inhotim (Brasil) y el Saint Louis Art Museum (EEUU). Se busca entender el papel de las colecciones allí presentes, a fin de evidenciar, a partir de la relación entre investigadores e interlocutores, las redes y posiciones que se constituyen.

Palabras clave: Apertura democrática, colecciones, higienización, silencios, hegemonía de clases. 